\title{
Yellow in English and “黄” in Chinese: A Cognitive Approach
}

\author{
Yang Xiaoyue, Jiang Zhaozi \\ Foreign Language School, Linyi University, Linyi, China \\ Email address: \\ 1171597205@qq.com (Yang Xiaoyue), amurry@163.com (Jiang Zhaozi)
}

\section{To cite this article:}

Yang Xiaoyue, Jiang Zhaozi. Yellow in English and “黄” in Chinese: A Cognitive Approach. International Journal of Language and Linguistics. Vol. 9, No. 2, 2021, pp. 32-38. doi: 10.11648/j.ijll.20210902.11

Received: March 4, 2021; Accepted: March 17, 2021; Published: March 26, 2021

\begin{abstract}
Color is closely related to people's lives, so it has become an indispensable part of the vocabulary now. This paper focuses on the research background, research purpose and significance of the color word "yellow" in Chinese and English, analyzing the entries from the perspective of cognitive linguistics, aiming to study the similarities, differences and the causes related. The author first collected and categorized entries through authoritative dictionaries of Chinese and English, and used the methods of comparative research, literature research and case analysis to elaborate commonalities and differences in word meanings. By researching the corresponding historical allusions and rhetorical methods, such as personification and symbols, we can feel the emotions expressed by the color words and deduce the evolution path of words' meaning. Through research, these conclusions can be drawn: 1) the meanings of "yellow" in Chinese and English are basically the same; 2) there is an unequal meaning between the two; 3) this unequal meaning is attributable and reflects the existence of two cultures values, cultural aesthetic and psychological differences. Through research, the aim is to allow learners to apply flexibly and accurately in cross-cultural business communication, daily life and linguistics learning, and to feel the charm of language.
\end{abstract}

Keywords: Colour Words, "Yellow”, Cognitive Linguistics, Unequal

\section{Introduction}

\subsection{Research Background}

If language is a bridge for humans to express emotions and convey information, then words are the reinforced concrete that constitutes the bridge, and color words add colorfulness to the bridge. Color is closely related to people's lives, so it has become an indispensable part of the vocabulary [1]. At the same time, due to the special nature of the non-independent existence, color words have become a category of concern. The Chinese and English language vocabulary of color is very rich. We should not only pay attention to their basic meaning, but also deeper layers. As one of the three primary colors, yellow has many characteristics such as wide range, high frequency, etc. Therefore, it has a very important position in the color vocabulary system.

This article takes yellow as an example, from the perspective of cognitive linguistics, specifically analyzing the equivalence and difference between "yellow" and “黄”, and briefly analyzing the cultural reasons for these differences.

\subsection{Research Significance and Purpose}

In the global village era, communications between diff erent countries, nationalities and cultures have become $\mathrm{m}$ ore and more frequent. People increasingly need to enga ge in various activities with who come from different $c$ ultural backgrounds. The significance and influence of th e "color phenomenon" in cross-cultural communication is gradually becoming more and more noticeable. We shou ld have an in-depth understanding of the deeper and wider unique connotations of different colors in different region $\mathrm{s}$, and make a comparative analysis of the different symbo lic meanings expressed by colors in China and the West, s $\mathrm{o}$ as to explore the cultural development of different natio nalities. [2] The cross-cultural study of color words has extremely important functions and practical significance.

Therefore, this article attempts to mainly explore the meaning of the color word "yellow" in English and “黄” in Chinese, and investigate the similarities and differences. In addition, this article will make an analysis of the reasons and 
causes for the differences, which will be helpful to understand each other in international communication.

\subsection{Research Questions}

This article aims to research the following questions:

1) What are semantic meanings of the phrases of color words?

2) What are similarities and differences of the color words?

3) What are the causes and reasons of these differences?

\subsection{Research Organization}

This paper consists of five chapters.

Chapter one gives a general introduction to the whole article. This chapter mainly talks about the research background, significance and purpose, and posing three major questions that need to be solved and the organization of the whole passage.

Chapter two talks about the theories related and rhetorical devices.

Chapter three mainly collects entries of color words from Oxford Advanced Learner's English-Chinese Dictionary mostly, and the rest of them were from other thesis or journalism and then classify them according to meaning.

Chapter four compares these color words, and then tries to find out causes and reasons.

Chapter five indicates limitations of the present study and proposes the prospects for the future research.

\section{Theories Related}

\subsection{Cognitive Linguistics}

The combination of cognitive science and linguistics, a new frontier discipline, cognitive linguistics, has become a hot topic in the last ten to twenty years. [3] Cognitive li nguistics is a branch of linguistics. Cognitive linguistics is nased on human experiences of the world and the wa $y$ they perceive and conceptualize the world. [4] Taking the second-generation cognitive science and experiential philosophy as the theoretical background, cognitive ling uistics was born on the basis of anti-mainstream linguist ics transformation and generative grammar, and began to take shape in the late 1980 s to the 1990s. Artificial int elligence, linguistics, psychology, system theory and so o $\mathrm{n}$ are included in cognitive linguistics, which aims at ge nerative linguistic talents and proposes that the creation, learning and use of languages must basically be able $t$ o through human cognition to explain, because the foun dation of human knowledge is cognitive ability. Languag e ability is an integral part of human cognitive ability, and language is not autonomous. [5] Cognitive linguistics is not a single language theory, but represents a research $p$ aradigm. As a collective term for multiple cognitive lan guage theories, it is characterized by treating people's da ily experience as the basis of language use, focusing on interpreting the inseparable link between language and general cognitive abilities. Although these linguistic theor ies are not the same, the basic assumptions on the lang uage are very similar, and they all endorse the basic vie wpoints mentioned in the previous section to varying de grees, but they differ in the specific linguistic phenomen a discussed and concerned. The main theoretical method s of cognitive linguistics are: "Construction Grammar" $b$ y Fillmore, Goldberg, etc.; "Cognitive Grammar" by Lan gacker; "Cognitive Semantics" by Lakoff, Talmy, etc.; an d Neurocognitive Linguistics by S. Lamb. The purpose i $\mathrm{s}$ to play the intellectual role of learners in language tea ching, to understand, discover, and master language rules through conscious study of phonetic, vocabulary, and gr ammatical knowledge, and to use the language comprehe nsively and creatively in terms of listening, speaking, re ading and writing.

\subsection{Rhetorical Devices}

\subsubsection{Description by Color}

Description by color refers to the use of color words to describe the colors of things. This is the most frequently and widely used rhetoric of color words in English and Chinese. Due to the similarity of objective environment and human body structure, people's perception of color words is roughly similar, so that the pragmatic functions of basic color words in English and Chinese are roughly the same. Its pragmatic function is mainly the function of applying color (the function of displaying objective color) and the function of expression (the function of conveying the subjective feelings of the cognitive subject). [6] It is common in literary works.

For example, "He dreamed of Africa when he was a boy and the long golden beaches and the white beaches, so white they hurt your eyes, and the high capes and the green brown mountain." (Ernest Hemingway, 1952: 29)

In the lines of the above example sentence, the reader seems to have a panoramic view of the magnificent nature. If the color words are removed, the whole description will be bland, pale, and lifeless.

\subsubsection{Symbol}

Borrowing a specific image to imply a specific character or affairs to express sincere feelings and profound allegories, this artistic expression of levying things is called symbol. The symbolic performance effect can enrich people's associations and make people get the infinite feeling of artistic conception; it can give people a concise and vivid real sense, and can express sincere feelings. There is no necessary connection between the ontological meaning and the symbolic meaning of the symbol, but through the artist's prominent depiction of the features of the ontological thing, the art appreciation will be associated with this and the other, and thus realize the meaning the artist wants to express. Symbols are different from metaphors. They are more extensive than general metaphors. Some works have artistic images that are even expressed in symbolic ways.

For example, in Chinese poems, autumn leaves and 
autumn wind mostly symbolize the sad mood of parting.

\subsubsection{Personification}

Personification or anthropomorphic rhetorical method refers to the rhetorical means of making things (including objects, animals, thoughts, or abstract concepts) into people so that they have the appearance, personality, or emotions of a person. Personification can be expressed through adjectives, verbs, or nouns.

What are the benefits of personification?

The use of anthropomorphic rhetorical method gives vitality or human characteristics to something, and vividly describes a certain characteristic of something. Moreover, the use of anthropomorphic rhetoric method can not only make the description of things more vivid, but also express the author's feelings for the things he describes.

Expressive effect: make readers feel that the objects described are more lively and close, and make the article more vivid.

\section{Data Collection}

This chapter is the most important part of the whole article. In this chapter, the entries of color words are mainly collected, and classifications are based on semantics. The data were collected from Oxford Advanced Learner's English-Chinese Dictionary mostly, and the rest of them were from other thesis or journalism.

\subsection{Phrases with Yellow}

Table 1. Phrases with Yellow.

\begin{tabular}{ll}
\hline Type & Example \\
\hline A. Colour & To turn yellow \\
B. Disease & Yellow fever \\
C. Geographic position & Yellow River \\
D. Honor & Yellow beltt \\
E. Wealth & Yellow boy \\
F. Warning & Yellow card \\
\hline & Yellow line \\
G. Illegal & Yellow Union \\
H. Commercial Telephone Number & Yellow-dog contracts \\
Book & Yellow pages \\
I. Newspaper style & Yellow press \\
J. Low-priced & Yellow back \\
K. Racial discrimination & Yellow race \\
L. Timidity & Yellow belly \\
M. Protest & Yellow flu \\
N. The road to succeed & Yellow brick road \\
\hline
\end{tabular}

The types and examples of English colour word "yellow" are shown below. Collection of yellow entries from the authoritative dictionary of English.

The "yellow" has 14 types of different terms in English. There is no special meaning in English that is more than other color, and its meaning tends to be derogatory. Sometimes yellow can mean danger and warning, such as "yellow alert" and "yellow card" in sports competition. In the sentence "David is to yellow to arrest the criminal", yellow has the meaning of cowardice. In English, "yellow journalism" means vulgar publications, but occasionally yellow means wealth, such as "yellow boy" referring to gold coins. ${ }^{1}$

\subsection{Phrases with 黄}

The types and examples of Chinese colour word “黄” is shown below.

Table 2. Phrases with 黄.

\begin{tabular}{|c|c|}
\hline Type & Example \\
\hline A. Colour & 黄色（Yellow in color） \\
\hline B. Disease & 黄㾝病（A disease of the liver） \\
\hline C. Geographic position & 黄河（China's mother river） \\
\hline D. Honor & 黄袍加身(To raise sb. to the purple) \\
\hline E. Wealth & $\begin{array}{l}\text { 黄金（Gold） } \\
\text { 黄白之物（Gold and silver） }\end{array}$ \\
\hline F. Warning & 黄牌（Yellow warning sign） \\
\hline G. Illegalinstitution & $\begin{array}{l}\text { 黄色工会（Pseudo trade union } \\
\text { organization controlled by Kuomintang } \\
\text { reactionaries before the liberation of } \\
\text { China） }\end{array}$ \\
\hline H. Ancestor in ancient time & 皇帝（The emperor） \\
\hline I. Auspicious & 黄道吉日（Auspicious day） \\
\hline J. Religion & 黄白之术（Taoist alchemy） \\
\hline $\mathrm{K}$. The young and the old & 黄童白舅（Young and aged） \\
\hline L. Precious & 黄金时代（The golden age） \\
\hline M. Obscene & 黄色电影（Blue film） \\
\hline N. Ethics & $\begin{array}{l}\text { 黄花晚节（A metaphor for virtuous } \\
\text { people in old age） }\end{array}$ \\
\hline O. Bumper harvest & 黄茂（Rich grain） \\
\hline
\end{tabular}

Based on the information collected, there are 20 different types of "yellow" meanings in Chinese. Some of them have unique significance in Chinese culture. The ancient Chinese civilization began in the Yellow River Basin, and the land is mainly yellow, which is the basis of all things, so the most primitive meaning of yellow in China is to symbolize the land. One of the earliest emperors was called “黄帝”, so the Chinese people regard yellow as the respect, claiming themselves to be the Chinese descendants. Later yellow was the representative of rights and status in feudal society, and “皇” in “皇帝” (The emperor) was also synonymous with “黄” and took its meaning.[7] Yellow was also designated as the clothing color of the emperor, and the ordinary people were forbidden to wear it, like yellow robes, especially the clothes of the emperor. The roofs of the royal building in the Ming and Qing dynasties were all yellow. Yellow is the symbol of wealth, and it is the color of gold, so we often use “黄白之物” (Gold and silver)to refer to money. In addition, in China, yellow means auspicious, as people often say “黄道吉日” (Auspicious day). But yellow also has very different meanings in Chinese, such as “黄牌” (Yellow warning sign), which means to warn; And “黄色电影” (Blue film), which indicates the depraved films.

There is no denying that Chinese and English cultures have certain similarities in their understanding of yellow. For example, yellow is used to symbolize wealth, “黄金”（Gold） in Chinese and gold in English. Yellow also has the meaning

\footnotetext{
${ }^{1}$ All table contents refer to the ninth edition of the Oxford English Dictionary.
} 
of warning, “黄牌” (Yellow warning sign) in Chinese and yellow card in sports competitions in English.

\section{Major Findings}

This chapter compares these color words and summarizes four patterns according to their semantic meanings, deeply analyzing the implied and derogatory and commendatory meaning behind the meaning of words through rhetorical methods such as symbolizing, personification, and then tries to find out causes and reasons from five aspects. And the ultimate goal of translation is to convey the "cultural information" of another language through language, rather than the transformation of language form in a simple sense. Color words contain rich cultural connotation, which can not be simply understood from the literal meaning in translation, but should be understood and selected from the different cultural connotation and extended meaning contained in color words. [8]

\subsection{Analysis on Semantic Meaning}

Through research and analysis, “黄” and "yellow" have the following four corresponding modes.

\subsubsection{Consistence of Semantic Meaning}

In terms of description of color, they are basically the same. Semantic universals do exist in the domain of color vocabulary. Moreover, these universals appear to be related to the historical development of all languages in a way that can be properly termed evolutionary. [9] “淡黄色” ( Pale yellow) can be replaced by pale-yellow in English. Besides, “黄” in China and yellow in English can represent disease, warning, illusory, depression, honor, as shown in the following table:

Table 3. The yellow represents the type.

\begin{tabular}{lll}
\hline Type & English & Chinese \\
\hline A. Disease & Yellow fever & 黄热病 \\
B. Warning & Yellow card & 黄牌 \\
C. Bleak & Symphony in Yellow & 黄花 \\
D. Honor & Yellow admiral & 黄袍 \\
\hline
\end{tabular}

“黄热病” in Chinese can be expressed as "yellow fever” in English; The phrase “黄牌” in China and "yellow card" in English to warn athletes who violate the rules in sports events. Yellow is associated with autumn. When the autumn comes, the yellow leaves of the tree fall and wither, everything in Eastern and Western cultures is associated with depression, decay, depression, death. In English literature, the most famous description of yellow is Symphony in Yellow, the 19th-century aestheticist poet and dramatist Oscar Wilder (1854-1900). Yellow appears in the whole passage four times, depicting London's declining autumn scenery, revealing depressing sadness; The sentence "I see that I am more gracile than the yellow flowers." from To the Tune of Intoxicated Under the Shadow of Flowers, written by the poet $\mathrm{Li}$ Qingzhao (1084-1155) in Song dynasty, “黄花” is an anthropomorphic art, referring to the sloppy appearance and the lonely night scene, expressing the sadness of the poet's heart.; Yellow symbolizes the right of the central government and the country, so yellow is the exclusive property of feudal emperors of all ages. "Yellow" can not be used casually. For example, “黄袍” is the emperor's “龙袍”. “Yellow admiral” also symbolizes honor in English, but the level of expression is different.

Therefore, “黄” in Chinese has many similarities with "yellow" in English.

\subsubsection{Corresponding of Semantic Meaning}

Associative meaning refers to the reader or listener's Association of words and a label for the internalization of words and phrases. [4] The word meaning associations have different literal meanings, but can cause the same cultural connotation.

Table 4. The word meaning association of yellow.

\begin{tabular}{|c|c|c|}
\hline Type & English & Chinese \\
\hline A. Noble & $\begin{array}{l}\text { To raise sb. to the purple } \\
\text { Blue blood }\end{array}$ & 黄袍加身 \\
\hline B. Obscene & Blue film & 黄色电影 \\
\hline C. To lack of experience & As green as grass & 黄毛Y头 \\
\hline
\end{tabular}

In China, “黄” symbolizes power, while English corresponds to "purple" and "blue". If sb. is associated with the royal family and has the royal lineage, we can say "He has blue blood." “黄” in Chinese also means corrupt and inferior, while in English corresponding to this meaning is "blue", for example, "blue film, blue gown, blue jokes"; “黄” in Chinese can be extended to have no experience, for example, “黄毛Y 头"(a silly little girl), while in English corresponds to "green". Westerners use green to mean young, naive, and inexperienced. For example, new sailors can be described by the phrases "a green man", "as green as grass".

\subsubsection{Conflict of Semantic Meaning}

Chinese and English cultures are different, and people in different cultures have different cognitive models for certain concepts. [10] The same word gives different cultural meanings and emotions or even the opposite meanings in different cultural backgrounds. Therefore, it is necessary to describe the specific situations in which different cognitive models are reflected in the understanding of color words.

Table 5. Different cultural meanings and emotions of yellow.

\begin{tabular}{lll}
\hline Classification Emotion Emotion & English Example & Chinese Example \\
\hline A. Animals & Ox (N.) & 黄牛(C./D.) \\
B. Plants & Camomile (N.) & 黄金菊(C.) \\
C. Star & Yellow star (D.) & 黄星 (C.) \\
D. Cloth & Yellow jersey (C.) & 黄马甲 (C.) \\
\hline C: Commendatory & & \\
N: Neutral & & \\
D: Derogatory & &
\end{tabular}

Plants and animals in Chinese have emotional significance through personalization, such as: ox, its righteousness meaning is a person who is hard-working, while its derogatory meaning refers to vendors who monopolize theater tickets, etc., and then sell them at high prices. Scalper in English can express this 
meaning. “黄菊” symbolizes steadfastness, it is commendatory; while most of the animals and plants represented by "yellow" in English have no associative meaning, and the objective natural attributes expressed are neutral words in emotional expression; “黄星” is the symbol of auspicious signs in Chinese, which is a commendatory term. While in English, it means a sign that the Nazi Germany required the Jews to wear. It is a derogatory term. “黄马夹” in Chinese refers to the highest gift given to a meritorious minister, while yellow jersey is a prize given to the winner in bicycle race, which are used in different scenarios.

\subsubsection{Vacancy of Semantic Meaning}

Because the members of different societies using different languages have different historical and cultural traditions and social and psychological backgrounds, the meanings of the words that denote the same thing sometimes change naturally in different languages. Thus, there are often words in one language that do not have equivalent words in other languages. [11] Word meaning gap is the non-corresponding phenomenon of words or word meanings between two languages. The difference between English and Chinese national cultures will inevitably lead to the formation of different vocabulary systems in English and Chinese. Different vocabulary systems will make it difficult for English and Chinese words and meanings to correspond one-to-one, resulting in "vacancy" in vocabulary or meaning. [12] Word sense vacancy is a phenomenon that is widespread and causes more difficulties in translation.

Table 6. Vacancy of Semantic Meaning.

\begin{tabular}{|c|c|c|}
\hline & Chinese Example & English Example \\
\hline $\begin{array}{l}\text { A. Chinese idiomatic folk } \\
\text { expressions }\end{array}$ & 黄梅戏 黄梅雨 & \\
\hline B. To be related to Yellow River & 黄泛区 & \\
\hline C. Timidity & & Yellow streak \\
\hline D. Religion & 黄白之术 & \\
\hline E. Ethics & 黄花晚节 & \\
\hline F. Low-priced & & Yellow covered \\
\hline $\begin{array}{l}\text { G. Ancestors in ancient time } \\
\text { H. The old and the young }\end{array}$ & $\begin{array}{l}\text { 皇帝 } \\
\text { 黄童白叟 }\end{array}$ & \\
\hline
\end{tabular}

Vacancy in cultural terms due to living environment and differences in life, such as Chinese folk language “黄梅戏”, which means a form of regional drama popular in central Anhui province; “黄梅雨”, which means intermittent drizzles in the rainy season in the middle and lower reaches of the Cangjiang River; and the “黄泛区” associated with the Yellow River. Lack of meaning due to differences in historical culture, such as “黄 帝”. It is said that he is the first emperor of the Chinese nation. “黄帝” is closely related to the yellow. In the history of the feudal dynasty in China for more than 2000 years, the Chinese have always advocated yellow. Yellow is often regarded as a symbol of monarchy. It is caused by different religious beliefs. Word vacancies, such as the word “黄白之术” related to the Taoist alchemy, while "yellow" in English symbolizes betrayal, because Judas, wearing a yellow robe in the Bible, sold Jesus for 30 silver coins, so "yellow" has a cowardly meaning, such as "yellow streak"; Confucianism pays attention to ethics and morals, such as “黄花晚节” (a metaphor for people to maintain noble morals in their old age); they pay attention to the traditional virtue of respecting the elderly and loving the young, words like “黄童白叟” and so on.

\subsection{Causes and Reasons of Discrepancy}

This article investigates the deep-seated reasons for the cultural differences and vacancies of the color words “黄” and "yellow" from the following five aspects.

\subsubsection{Geographical Differences}

The birthplace of Chinese civilization is the loess plateau in the middle and upper reaches of the Yellow River, where the land and river water are dominated by yellow. Therefore, people have a preference for this color and think that yellow is a kind of advanced color in subjective consciousness. [13]

Yellow has more meanings than most color words in Chinese, however, the meaning of yellow in English is different from that of yellow in Chinese in many ways. In addition to its physical color, it has no broader meaning than other words, and its extended meaning is often derogatory. [13]

Moreover, the West does not have this special geographical environment, and Western culture was born in the sea waves. The initial stage of Englishization was Europe on the west side of Eurasia, and the southwest and north sides were surrounded by the sea. The ocean became the birthplace of European civilization. Due to the difficult living conditions, people have to turn to the mysterious and turbulent sea, in exchange for maritime trade for subsistence. The open marine geographic environment has created an enterprising cultural character and cultivated the basic character of advocating freedom and individual independence. Therefore, in English culture, there are many words related to the blue of the sea. For example, a family with royal descent is "a blue-blooded family". In the past, the Guardian Medal awarded to the heroes by the British government was decorated with "blue ribbons", and the Royal Navy and police were wearing "blue uniforms".

When it comes to skin color, the East Asian race is yellow, while the western race is white, so in western area, "yellow" has no corresponding noble meaning.

\subsubsection{Historical Differences}

Legend has it that the goddess in Chinese mythology created humanbeings from mud and water, imitating her own image. Therefore, the creation of man made by loss is a symbol of the human origin of the Han nationality. The creation of man made by loess reflects the relationship between human origin and color. These are recorded in the Huai Nan Zi and Shan Hai Jing. “黄帝” is the first emperor of the Chinese nation in legend. When he was the emperor, God once blessed the auspiciousness of the earth. Because the soil is yellow, people in the world called him Huangdi. Therefore, in the feudal dynasty of China for more than 2000 years, the Chinese have been worshiping yellow, which is often regarded as a symbol of monarchy. In the Zhou Dynasty, “黄钱” was 
used as a symbol of emperor's power. After the Sui Dynasty, the emperor wore a yellow dragon robe. Yellow became the exclusive color of the monarch

With the material conditions, the superiority of the living environment, and the stability and stereotypes of customs, traditional agriculture has kept people confined to limited, scattered land, repeating the rules of daily life from sunrise to sunset. At the same time, agricultural production is mainly less creative. Elderly and experienced elders are often elected as leaders or authorities, which leads to the natural worship of elder family leaders, respect for tradition, and passive acceptance of ancestral experience. These are reflected in Huang's entry, Such as “黄雀衔环” ( An idiom expressing gratitude ) ; At the same time, empirical agricultural production has created a strict and stable patriarchal and ethical order, such as the cultural psychology of the succession, which is reflected in Huang's expression of "pure" entries, such as: “黄童白舅” (Young and aged) Agricultural production required people to reduce migration. The Han people who had been loyal to the loess for generations were happy. The love of their hometown weakened the national adventure and the worship of the land and gave birth to the rites of the community. The feudal society emperor held community events every year, which played an important role in the country's religious activities. For example, “黄花 晚节”( A metaphor for virtuous people in old age), so the Han people respect the ancestors and worship the ancients, and pay attention to traditional experience and practice.

In the West, yellow has no such history. Because Western culture has always respected the Bible, and the thoughts in the Bible are deeply rooted in the hearts of the people. Yellow is reminiscent of the color of the clothes worn by Judas, a betrayal of Jesus, so yellow has a bad symbolic meaning. It mainly means despicable and timid, such as "yellow dog"; [14] "yellow streak" and "yellow-livered" also mean timid.

\subsubsection{Cultural Differences}

To communicate effectively and smoothly, we must combine language knowledge with cultural knowledge $(\mathrm{Hu}$ Wenzhong, 1997). The Chinese and English cultural traditions are different, forming the cultural orientation of "shame" or "feeling" of the Confucian culture of the Han people and the cultural orientation of "guilt" of the self-identification of English.

Confucian culture is the mainstream of Han culture. From ordinary people's introspection to self-cultivation to the personality requirements of the ruler, people's moral consciousness is the primary condition, and virtue is the highest state of realizing the value of life. Respect for human standards, such as words “黄卷青灯” ( An idiom used to describe studying hard at night) , “黄魂” ( The spirit of the Han nation) etc. The Han people are in the obligation standard, with a weak concept of rights and a strong sense of obligation.

Christian culture is the mainstream of English. The English always protect their lawful rights and interests from infringement. When necessary, they even use law to defend its legitimate interests. Jesus is the superman of Western culture. His philosophy is the philosophy of an extraordinary, divine. From the perspective of Christianity, the love of God is the highest form of love in the spirit, and it is essentially different from all kinds of love between people. So Judah in the yellow robe mentioned above is considered a symbol of evil and cowardice.

\subsubsection{Accidental Factors in Social Development}

No matter what kind of obscene books and audiovisual products, we call them “黄色” (yellow). They are called this way not because they originally used yellow covers or packaging, but because of their carrier. In the 19th century, two American newspapers competed for vulgar comic strips to increase sales. One of the newspapers was called The Yellow Child, and it was later called the Yellow Paper. Later, books and newspapers containing pornography and violence were called “黄色报纸”（scandal sheet） and “黄色杂志” (scandal sheet), and the term has been used. Later, “黄色电 影”（Blue film） appeared. This should be the original source of the extended meaning of “黄” in the Chinese language, while the meaning of "yellow" has not been passed down in the English-speaking world, and the word has spread in Chinese, with a large chance factor. So When it comes to the word "yellow", Chinese will immediately associate it with words related to sex such as "low and obscene" and "obscene and vulgar", or unhealthy books, periodicals, works, songs, pictures, videos and so on. [15] Just like the butterfly effect, the use of "黄" in Chinese has been passed down ten times, and the government has officially adopted it as a pronoun for pornography, which has made yellow dirty.

\subsubsection{The Mode of Thought}

The West values rationality, objectivity, and individuality, paying attention to subdivided and precise thinking. Chinese prefers perceptual, habits from large to small, from generalization to specificity, and inductive analysis to form a whole-to-part thinking mode. For example, euphemistic evaluation of others is a manifestation of Chinese culture, while English uses direct expression.

\subsection{Summary}

From the above research, we can see that “黄” in Chinese and "yellow" in English have four different cultural semantic correspondence modes, and studied the reasons for these similarities and differences, analyzing the path of word meaning evolution.

\section{Conclusion}

This article takes “yellow" in English and “黄” in Chinese as examples. Through a comparative analysis of the different meanings of the color words in Chinese and English cultures, it reveals the differences in geography, history, culture, psychology and social development between China and the West, which will help some cross-cultural communication. 


\subsection{Limitations of the Present Study}

Due to objective conditions and time constraints, some issues are too late to do in-depth investigation and analysis. For example, the study of color words, especially in the context of different languages and cultures, needs to involve all aspects of color word attributes, such as grammatical attributes, semantic attributes, and pragmatic attributes. What is important is that the organic combination of several aspects requires unremitting efforts. Due to the limitation of entry collection, the richness and ambiguity of the emotional meaning of Chinese entries, and the differences and uniqueness of individual perception, this paper still has many deficiencies. I also hope that I can get the guidance and help of experts and teachers.

\subsection{Suggestions for Future Study}

It is hoped that in future research, color words will be compared in accordance with the principles of micro and macro combination, personality and commonality combination, theory and practice combination, teaching and scientific research.

\section{References}

[1] Berlin B. Kay, Paul. 1999. Basic Color Terms: Their Universality and Evolution [M]. America: Centre for the Study of Language\&Information, pp 103.

[2] Zhang Xiaoqin. A Brief Analysis of the Unique Symbolic Meaning of Chinese and Western Cultural Words [J]. Journal of Shandong Radio and TV University, 2019 (1): 41-43.

[3] Zhong Shouman. Semantic cognition and semantic structure of color words $[\mathrm{J}]$. Foreign Language Teaching, 2001 (4): $37-42$.

[4] Leech, Jeoffery (1891): The Study of Meaning, Longman,
London and New York. Geoffrey n. Leach (1985): semantics, Shanghai Foreign Language Education Press.

[5] Wang Yin. What is Cognitive Linguistics [M]. Shanghai Foreign Language Education Press, 2011.

[6] Yan Qinxia, A Contrastive Study of Basic Color Words in English and Chinese [D] Central China Normal University, 2003.

[7] Zhang Chunhong, The Core Color Word "Yellow" in Chinese from the Perspective of Cognitive Linguistics [A] Huaxia Forum, 2016.

[8] Li Dan. Translation of Color Words in the Context of Chinese and Western Cultural Differences [J]. Overseas English, 2018: 132-133.

[9] Hu Zhuanglin. LINGUISTICS [M]. Beijing: Peking University Press, 2017.

[10] Zhu Li. Research on the Cognitive Pattern of Chinese Color Word Translation: A Cognitive Linguistic Perspective [D]. Liaoning: Liaoning Normal University, 2006.

[11] Xiao Liangrong. On Cultural Disequivalence of Colour Words in English and Chinese [J]. Journal of Shantou University, 1999 (6): 66-70.

[12] Bai Hong A Study of English and Chinese Polysemy Phenomena Based on Cognitive Linguistics [J]. Teaching and Management, 2012 (30): 89-90.

[13] Chen Jing. Cultural Differences between China and the West from the Perspective of "Yellow" and "Yellow" [J]. Science and Technology Information, 2013 (7), 239-234.

[14] Yang Chunhui. The Difference of the Meaning of Yellow in Chinese and English [J]. Science, Education and Culture, 2003: 23.

[15] Jiang Dong yuan. On the Cultural Differences of Color and Color Words $[\mathrm{J}]$. Journal of Sichuan International Studies University, 2002 (2): 139. 